\title{
Upregulation of FOXM1 leads to diminished drug sensitivity in myeloma
}

Chunyan Gu ${ }^{1,3}$, Xuefang Jing ${ }^{3}$, Carol Holman ${ }^{3}$, Ramakrishna Sompallae ${ }^{3,4}$, Fenghuang Zhan ${ }^{5,6}$, Guido Tricot ${ }^{5,6}$, Ye Yang ${ }^{1,2^{*}}$ and Siegfried Janz $z^{3,6,7^{*}}$ (D)

\begin{abstract}
Background: Following up on previous work demonstrating the involvement of the transcription factor forkhead box M1 (FOXM1) in the biology and outcome of a high-risk subset of newly diagnosed multiple myeloma (nMM), this study evaluated whether FOXM1 gene expression may be further upregulated upon tumor recurrence in patients with relapsed multiple myeloma (rMM). Also assessed was the hypothesis that increased levels of FOXM1 diminish the sensitivity of myeloma cells to commonly used myeloma drugs, such as the proteasome inhibitor bortezomib (Bz) and the DNA intercalator doxorubicin (Dox).
\end{abstract}

Methods: FOXM1 message was evaluated in 88 paired myeloma samples from patients with nMM and rMM, using gene expression microarrays as measurement tool. Sources of differential gene expression were identified and outlier analyses were performed using statistical methods. Two independent human myeloma cell lines (HMCLs) containing normal levels of FOXM1 $\left(\right.$ FOXM1 ${ }^{\mathrm{N}}$ ) or elevated levels of lentivirus-encoded FOXM1 (FOXM1 ${ }^{\mathrm{Hi}}$ ) were employed to determine FOXM1-dependent changes in cell proliferation, survival, efflux-pump activity, and drug sensitivity. Levels of retinoblastoma (Rb) protein were determined with the assistance of Western blotting.

Results: Upregulation of FOXM1 occurred in 61 of 88 (69\%) patients with rMM, including 4 patients that exhibited $>20$-fold elevated expression peaks. Increased FOXM1 levels in FOXM1 ${ }^{\mathrm{Hi}}$ myeloma cells caused partial resistance to $\mathrm{Bz}$ (1.9-5.6 fold) and Dox (1.5-2.9 fold) in vitro, using FOXM1 ${ }^{\mathrm{N}}$ myeloma as control. Reduced sensitivity of FOXM1 ${ }^{\mathrm{Hi}}$ cells to Bz was confirmed in vivo using myeloma-in-mouse xenografts. FOXM1-dependent regulation of total and phosphorylated Rb agreed with a working model of myeloma suggesting that FOXM1 governs both chromosomal instability (CIN) and E2F-dependent proliferation, using a mechanism that involves interaction with NIMA related kinase 2 (NEK2) and cyclin dependent kinase 6 (CDK6), respectively.

Conclusions: These findings enhanced our understanding of the emerging FOXM1 genetic network in myeloma and provided preclinical support for the therapeutic targeting of the FOXM1-NEK2 and CDK4/6-Rb-E2F pathways using small-drug CDK and NEK2 inhibitors. Clinical research is warranted to assess whether this approach may overcome drug resistance in FOXM1 ${ }^{\mathrm{Hi}}$ myeloma and, thereby, improve the outcome of patients in which the transcription factor is expressed at high levels.

Keywords: Plasma-cell neoplasm, Targeted cancer therapy, Small-drug inhibitor, Cellular senescence

\footnotetext{
*Correspondence: yangye876@sina.com; sjanz@mcw.edu

Chunyan Gu and Xuefang Jing are co-first authors.

Ye Yang and Siegfried Janz are co-senior authors.

${ }^{1}$ The Third Affiliated Hospital, Nanjing University of Chinese Medicine,

Nanjing 210023, China

${ }^{3}$ Department of Pathology, The University of lowa Roy J. and Lucille A. Carver

College of Medicine, lowa City, lowa 52242, USA

Full list of author information is available at the end of the article
}

(c) The Author(s). 2018 Open Access This article is distributed under the terms of the Creative Commons Attribution 4.0 International License (http://creativecommons.org/licenses/by/4.0/), which permits unrestricted use, distribution, and reproduction in any medium, provided you give appropriate credit to the original author(s) and the source, provide a link to the Creative Commons license, and indicate if changes were made. The Creative Commons Public Domain Dedication waiver (http://creativecommons.org/publicdomain/zero/1.0/) applies to the data made available in this article, unless otherwise stated. 


\section{Background}

With an estimated 30 thousand cases annually, newly diagnosed multiple myeloma (nMM) is the second most common blood cancer in the United States [1]. MM is a neoplasm of immunoglobulin-producing plasma cells that reside in the bone marrow. Quintessential disease manifestations include serum M-spikes (paraproteins), lytic bone lesions, hypercalcemia and renal insufficiency [2]. Owing to both newly developed myeloma drugs and the continuous refinement of therapeutic regimens that combine high-dose chemotherapy (HDT) with autologous hematopoietic stem cell transplantation (ASCT), the outcome for patients with nMM has significantly improved in recent years [3] - making it possible, at long last, to cure a tangible number of patients [4]. However, in the great majority of cases, following a period of successful therapy, myeloma relapses as a drug-refractory aggressive disease that leaves few, if any, therapeutic options. The unmet medical need of relapsed multiple myeloma (rMM) warrants dedicated research to enhance our understanding of the underlying pathways and identify new molecular targets for the design and testing of novel treatment approaches.

Although potent myeloma treatments, particularly proteasome inhibitors (PIs) and immunomodulatory drugs (IMiDs), have given the means to durable responses and prolonged survival of patients with myeloma, the inevitable relapse with drug-resistant disease is all too common. The root cause of acquired drug resistance in rMM is poorly elucidated, yet increasing evidence points to the involvement of a complex population dynamic of neoplastic myeloma growth [5] characterized by competition of co-existing tumor cell clones that eventually give rise to a dominant treatment-refractory clone able to thrive under conditions of strong drug-induced selective pressure. Genetic and genomic studies have shown that the evolutionary process sketched out above is driven by point mutations in drug response and other genes [6], copy number alterations that can abrogate tumor suppressor pathways [7] and changes in the epigenome that can reshape phenotypic and functional features of myeloma cells by virtue of affecting gene expression [8]. Another driver of the intricate pathophysiology of rMM is the bone marrow microenvironment, which provides tumor-promoting interactions with resident bone cells and the innate and adaptive immune system [9]. Increased cancer stemness may also be involved [10], the annoying elusiveness of bona fide myeloma stem cells notwithstanding.

Heartened by recent findings on the key role of the transcription factor, forkhead box M1 (FOXM1), in the genetic network of myeloma [11], we here continue with previous studies on the impact of FOXM1 in nMM [12] and rMM [13] and show that acquisition of drug resistance may be an important mechanism by which FOXM1 facilitates disease progression and relapse. Upregulation of FOXM1 rendered human myeloma cell lines (HMCLs) in continuous in vitro culture partially resistant to the PI, bortezomib (Bz), and the DNA intercalator, doxorubicin (Dox). In agreement with that was the in vivo result that enforced expression of FOXM1 in a HMCL designated CAG reduced the sensitivity of myeloma-in-mouse xenografts to $\mathrm{Bz}$. We also provide evidence that FOXM1, presumably by virtue of its interaction with the retinoblastoma $(\mathrm{Rb})$ cell cycle progression and tumor suppressor protein, promotes $\beta$-galactosidase $\left(\beta\right.$-gal $\left.{ }^{+}\right)$activity in myeloma - the classic $\mathrm{Rb}$-regulated phenotype of cellular senescence that is mechanistically linked to relapsed cancer by means of acquired drug resistance, cancer dormancy and cancer stemness [14]. The result of this study adds strength to the contention that the therapeutic targeting of FOXM1 may benefit patients with myeloma in which the transcription factor is strongly expressed.

\section{Methods \\ FOXM1 expression in myeloma and treatment of patients with myeloma}

Levels of FOXM1 mRNA in myeloma cells were determined using Affymetrix U133Plus 2.0 microarrays (Santa Clara, CA) as previously described $[15,16]$. Statistical analysis of microarray data relied on GCOS1.1 software (Affymetrix, Santa Clara, CA). Patients at UAMS were treated using the Total Therapy 2 regimen, the backbone of which is high-dose melphalan therapy (HDT) and autologous stem cell transplantation (ASCT). Half of the patients received thalidomide both during intensive therapy and as maintenance therapy. The therapeutic approach to relapsing disease was not uniform and depended mainly on the time to relapse, the pace of relapse (slow versus aggressive), the presence or absence of organ dysfunction, and the patient's overall health status, physical and mental fitness and treatment preference.

\section{Human myeloma cell lines (HMCLs), myeloma drugs, and other agents}

Four IgA-producing HMCLs, designated CAG, XG1, H929 and ARP1, were included in this study. The identity of the cell lines was validated as previously described [12], using chromosomal translocation status and gene expression spikes as main parameters. Cells were propagated in vitro at $37{ }^{\circ} \mathrm{C}$ and $5 \% \mathrm{CO}_{2}$ using RPMI1640 cell culture medium (Gibco) supplemented with $10 \%$ heat-inactivated fetal bovine serum (Atlanta Biologicals) and antibiotics (100 units $/ \mathrm{mL}$ penicillin and $100 \mu \mathrm{g} / \mathrm{mL}$ streptomycin, Sigma). In some experiments, CAG and XG1 cells over-expressing FOXM1 $\left(\mathrm{FOXM1}{ }^{\mathrm{Hi}}\right.$ ) were compared to cells containing normal amounts of FOXM1 $\left(\mathrm{FOXM1}{ }^{\mathrm{N}}\right.$ ) [12]. In other experiments, H929 and ARP1 cells in which 
FOXM1 expression had been knocked down using shRNA $\left(\mathrm{FOXM} 1^{\mathrm{Lo}}\right.$ ) were compared to parental FOXM1 ${ }^{\mathrm{N}}$ cells [12]. Chemicals including myeloma drugs were purchased from Sigma (doxorubicin [Dox], thiostreptone [TS]), Millennium Pharmaceuticals (bortezomib [Bz]), or Invitrogen (propidium iodide, RNase A).

\section{In vitro assays using $\mathrm{HMCLs}$}

For cell cycle analysis, cells were fixed in ice-cold ethanol $\left(1 \mathrm{~h}, 4{ }^{\circ} \mathrm{C}\right)$, washed in PBS, re-suspended in propidium iodide (PI) solution $\left(40 \mu \mathrm{g} / \mathrm{ml}, 3 \mathrm{~h}, 4{ }^{\circ} \mathrm{C}\right)$ supplemented with $50 \mu \mathrm{l}$ RNase A $(10 \mu \mathrm{g} / \mathrm{ml})$, and evaluated by flow cytometry using a FACScan (Becton Dickinson, San Jose, CA). For determination of clonogenicity, $10^{4}$ myeloma cells were seeded in soft-agar plates (0.5 ml RPMI1640 supplemented with $0.33 \%$ agar and $10 \%$ FBS) and grown for 2 weeks at $37{ }^{\circ} \mathrm{C}$ and $5 \% \mathrm{CO}_{2}$ - in some cases exposed, during week 2, to myeloma drugs. Myeloma clones, defined as tight aggregates of $\geq 40$ tumor cells, were enumerated on digital images of soft-agar plates analyzed with the help of Image J. For measurement of proliferation and viability, cells were counted using a hemocytometer and evaluated for exclusion of trypan blue $(0.4 \%$ dye in PBS, $\mathrm{pH}$ 7.3), respectively. For determination of apoptosis, the flow-cytometric Annexin V APC assay (eBioscience, San Diego, CA) was used according to the manufacturer's instructions. For determination of drug-efflux capacity, the flow-cytometric efluxx- $\mathrm{ID}^{\mathrm{mat}}$ multidrug resistance assay was employed. MCF7 human breast cancer cells were included as benchmark. For determination of senescenceassociated $\beta$-galactosidase ( $\beta$-gal) activity, a kit from Cell Signaling Technology (Cat\# 9860) was used. Briefly, cells were fixed (15 min), washed (PBS) and incubated in $\beta$-gal staining solution overnight at $37{ }^{\circ} \mathrm{C}$.

\section{Western blotting}

Protein levels were determined by Western analysis using antibodies to FOXM1, Rb and $\mathrm{pRb}$ obtained from Santa Cruz Biotechnology (FOXM1, sc-500) or Cell Signaling Technology (Rb, 9309; pRb, 8515). Cells were lysed with assistance of the Mammalian Cell Extraction kit (K269-500) from Biovision, Milpitas, CA. 10- $\mu \mathrm{g}$ samples of protein were fractionated on 4-12\% SDS-PAGE gels, followed by transfer to nitrocellulose membranes blocked with $5 \%$ non-fat dry milk in Tris-buffered saline containing $0.05 \%$ Tween-20. Incubation with primary antibodies occurred overnight at $4{ }^{\circ} \mathrm{C}$. Proteins were visualized using HRP-conjugated secondary antibody and SuperSignal West Pico (Pierce, Rockford, IL). Membranes were subsequently stripped and re-probed for $\beta$-actin (Santa Cruz Biotechnology, sc-47778), which served as loading control.

\section{$\mathrm{HMCL}$ xenografting in NSG mice}

To compare the drug response in CAG myeloma cells expressing normal and elevated FOXM1 levels, respectively, $2 \times 10^{6}$ FOXM1 $^{\mathrm{N}}$ and FOXM1 ${ }^{\mathrm{Hi}}$ cells were injected subcutaneously (SC) into the right or left flank of NSG mice (Jackson Laboratory, Bar Harbor, Maine). Viability of FOXM1 $^{\mathrm{N}}$ and FOXM1 ${ }^{\mathrm{Hi}}$ cells was comparable $(\geq 90 \%)$. Seven days later, one group of mice was treated with bortezomib $(1 \mathrm{mg} / \mathrm{kg})$ administered intraperitoneally (IP) twice weekly. Another group of mice, designated untreated control, was injected with drug vehicle, normal saline $(0.9 \%$ sodium chloride). In all cases, tumor growth was measured using a pair of calipers. Mice were sacrificed for humane reasons using $\mathrm{CO}_{2}$ asphyxiation when tumors reached $20 \mathrm{~mm}$ in diameter. All studies were approved under protocol 1301010 of the Institutional Animal Care and Use Committee of the University of Iowa.

\section{Statistical analysis}

Two-tailed Student's t-test was used to compare two experimental groups, employing parametric or non-parametric methods in case data were normally distributed or not, respectively. One-way analysis of variance (ANOVA) was used to evaluate more than two groups. To compare drug responses in mice, linear regression and AUC (area under curve) determination were used. For all analyses, the GraphPad Prism 7 software package (La Jolla, CA) was employed and $p \leq 0.05$ was considered significant.

\section{Results}

FOXM1 message is elevated in most but not all relapsed myelomas

Using the University of Arkansas for Medical Science (UAMS) Total Therapy 2 (TT2) dataset (GSE2658) as discovery tool, we recently reported that upregulation of FOXM1 was a common feature of patients with rMM [13]. Here we confirm this finding with the help of an updated TT2 dataset that includes 127 patients with rMM and a related TT3 dataset that includes 30 patients with rMM - both available at GSE31161 (Fig. 1a). The increase in median FOXM1 mRNA levels in these datasets, 2.7-fold in case of TT2 (76/28) and 2.3-fold in case of TT3 (330/143), was very similar to the one observed in the original TT2 dataset (2.89-fold; 79.5/27.5). Furthermore, in all 3 datasets, mean FOXM1 expression at relapse was significantly elevated $\left(p=10^{-3}\right)$ compared to baseline. Next, we went back to the TT2 / GSE2658 dataset, presented in dot plot format in Fig. 1b, to visualize the two expression values, ND vs $\mathrm{R}$, for each patient. Upregulation of FOXM1 mRNA at relapse was seen in more than two thirds of patients (61 of $88,69 \%$; indicated by dots above the diagonal line), whereas gene message was down in $20(23 \%)$ patients (dots below the 
A

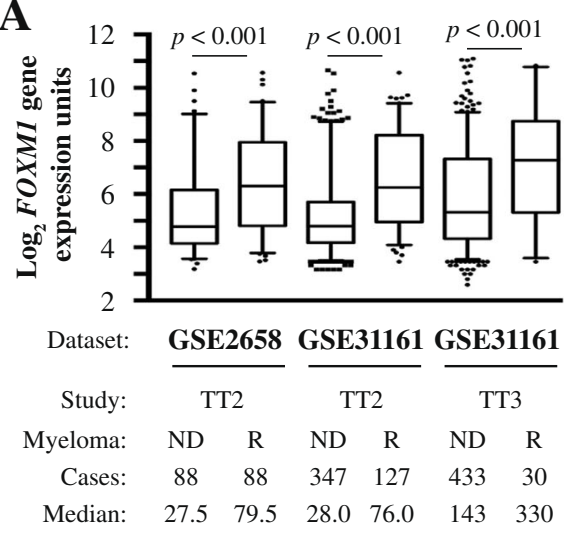

C

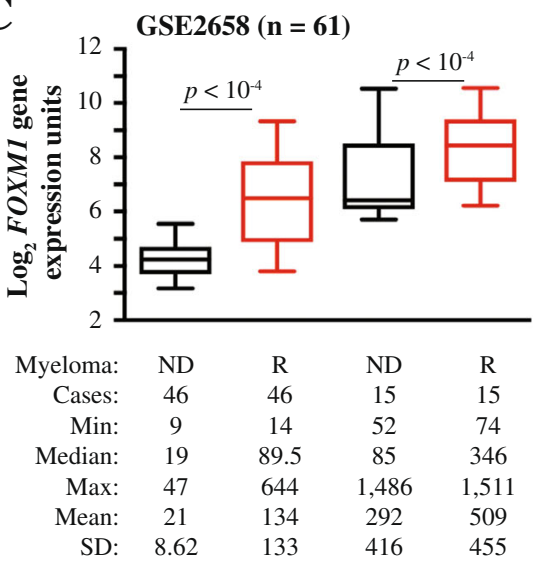

D

GSE2658 $(n=61)$

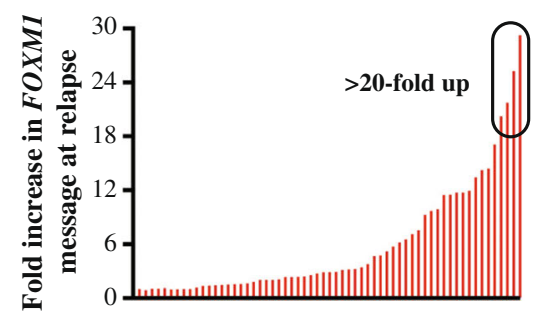

B

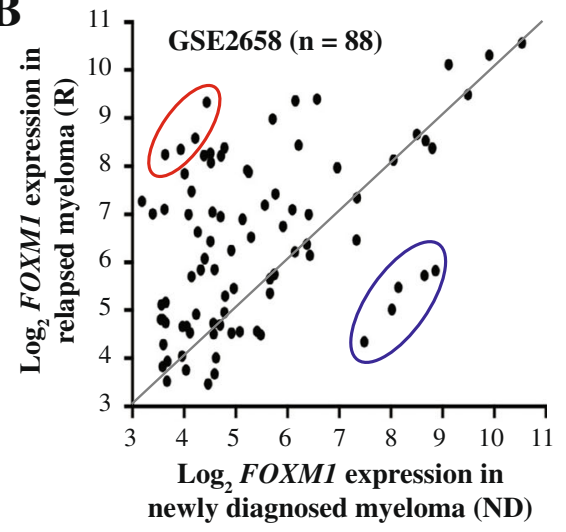

E

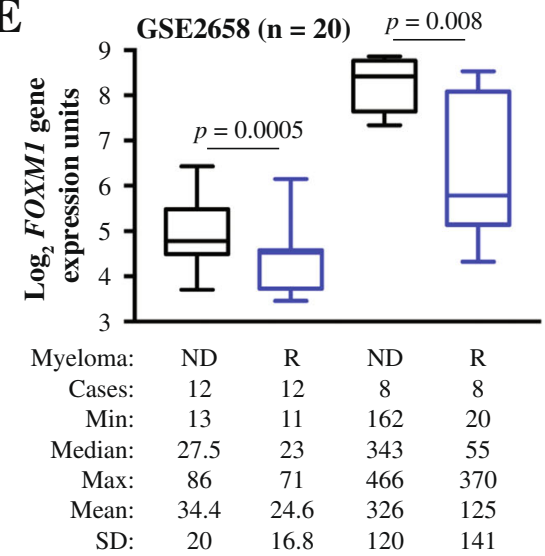

F

GSE2658 $(n=20)$

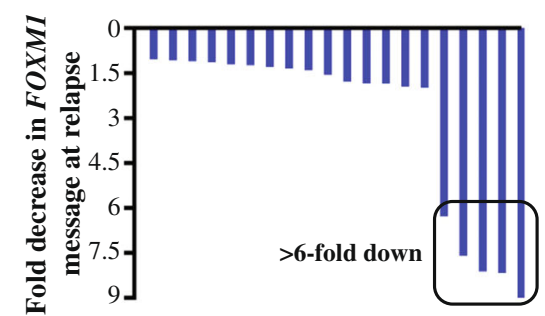

Fig. 1 FOXM1 message levels in paired samples of new and relapsed myeloma. a FOXM1 message is elevated in relapsed myeloma in UAMS datasets. Shown are box plots of FOXM1 mRNA levels from Total Therapy 2 (TT2) and Total Therapy 3 (TT3) datasets. For each dataset, FOXM1 expression at baseline in newly diagnosed disease (ND) is compared to relapsed disease (R). Median FOXM1 expression is indicated by a black horizontal line within the box. The 25th and 75th percentiles are indicated by lower and upper horizontal lines, respectively. Number of patients and median FOXM1 expression are given at the bottom. Statistical comparisons relied on the Mann-Whitney test. b Dot plot of paired ND and R myelomas $(n=88)$ from the TT2 / GSE2658 dataset. Dots above $(n=61)$ and below $(n=20)$ the black horizontal line indicate up- and downregulation of FOXM1 at relapse, respectively. Dots on that line $(n=7)$ represent patients with no change. Four $\mathrm{R}$ myelomas featuring a more than 20-fold elevation of gene message and five R myelomas exhibiting a more than 6-fold drop in gene expression are denoted by red and blue ellipse, respectively. These cases are also singled out in panels D and F, respectively. c Source of elevated FOXM1 at relapse. Shown is the breakdown of 61 myelomas with heightened levels of FOXM1 at relapse in two groups distinguished by lower (left) and higher (right) baseline expression. $\mathbf{d}$ Outliers with peak expression levels at relapse. Four myelomas exhibiting increases by more than 20-fold are indicated by black ellipse. e Source of decreased FOXM1 at relapse. Shown is the breakdown of 20 myelomas with reduced FOXM1 expression at relapse in two groups distinguished by lower (left) and higher (right) baseline expression values. f Outliers with steep drops in gene expression at relapse. Five myelomas exhibiting decreases by more than 6-fold are indicated by black ellipse

line) and unchanged in 7 (8\%) patients (dots on the line). The magnitude of the elevation at relapse ( 2.6-fold; 226/ $87.8)$ was similar to the decline ( 2.3-fold; 151/64.6) using mean expression levels for comparison. These results indicated that the overall increase of FOXM1 message at relapse was caused by the preponderance of myelomas with 
elevated gene expression (69\%), not by the circumstance that the magnitude of elevation exceeded that of reduction.

\section{Outlier analysis of FOXM1 expression in rMM}

To analyze the 61 myelomas that harbored elevated FOXM1 at relapse in greater depth, we partitioned these cases in two arbitrary groups defined by median baseline expression levels of 19 microarray units $(n=46)$ and 85 units $(n=15)$, respectively, in newly diagnosed (ND) disease (Fig. 1c, black boxes with whiskers). The increase at relapse in the low expresser group was somewhat higher (4.7-fold, 89.5/19) than in the high expresser group (4.1-fold, 346/85). The difference was due, in no small measure, to four myelomas in the low expresser group that exhibited $>20$-fold elevated expression peaks at relapse. This is indicated by a black ellipse in Fig. 1d. The analysis of tumors featuring reduced FOXM1 expression at relapse is depicted in Fig. 1e. Partitioning of the dataset $(n=20)$ in two groups with median baseline expression of 27.5 units $(n=12)$ and 343 units $(n=8)$ at the time of diagnosis (ND) demonstrated that the decrease in the high expresser group was more pronounced (6.2-fold, 343/55) than in the low expresser group (1.2-fold, 27.5/23; Fig. 1e). The difference could be attributed in large part to a subset of myelomas in the high expresser group $(n=5)$ that exhibited $>6$-fold drops in gene expression at relapse (Fig. 1f, black ellipse). These findings led us to conclude that the pattern of FOXM1 expression in rMM is heterogeneous, with outliers in both directions contributing disproportionally to the relapse-dependent shift in gene expression. To confirm the findings presented in Fig. 1 with an independent method not relying on Affymetrix arrays, we used RT-PCR to analyze sequential ND and R CD138 ${ }^{+}$ bone marrow tumor samples from 8 patients with myeloma undergoing HDT/ASCT therapy. Although the number of clinically confirmed relapses was low $(n=3)$, the increase in FOXM1 expression was impressive, up to 35-fold (Additional file 1: Figure S1).

\section{FOXM1 promotes proliferation and drug efflux activity of myeloma cells}

To assess the biological outcomes of elevated FOXM1 in MM, we relied on two HMCLs, XG1 and CAG, as experimental model system. The cells were manipulated to contain either elevated levels of FOXM1 $\left(\mathrm{FOXM} 1^{\mathrm{Hi}}\right)$ or normal levels of gene message and protein $\left(\mathrm{FOXM1} 1^{\mathrm{N}}\right.$ ) due to transfection with a human FOXM1 (isoform C) expressing lentivirus or a non-coding "empty" lentivirus (used as control), respectively [12] (Fig. 2a). Flow cytometric determination of cell proliferation showed that upregulation of FOXM1 promotes cell cycle progression (Fig. 2b). FOXM1 ${ }^{\mathrm{Hi}} \mathrm{CAG}$ and XG1 cells exhibited 14 and $13 \%$ higher growth rates, respectively, compared to FOXM1 ${ }^{\mathrm{N}}$ cells (compare columns labeled "Co"). Treatment of cells with the FOXM1-inhibiting thiazole antibiotic, thiostrepton (TS) [17], slowed the growth of both $\mathrm{FOXM1}^{\mathrm{Hi}}$ and FOXM1 ${ }^{\mathrm{N}}$ cells. However, the low Hi-to- $\mathrm{N}$ ratio indicated that FOXM1 ${ }^{\mathrm{Hi}}$ cells were more sensitive to TS than FOXM1 ${ }^{\mathrm{N}}$ cells (columns labeled "TS"). Figure 2c depicts an example of the magnitude of TS-dependent growth inhibition of $\mathrm{FOXM}^{\mathrm{Hi}}$ cells under conditions of higher drug concentration compared to panel B. The decrease in proliferation amounted to $72 \%(4.72 / 16.9)$ in case of CAG cells (left panel) and $76 \%(6.40 / 26.1)$ in case of XG1 cells (right panel). The results presented above were in line with genetic evidence gleaned from transcriptomic studies using microarrays, indicating that FOXM1 promotes myeloma proliferation. Thus, FOXM1 expression is positively correlated (Pearson's $r=0.712, p<10^{-4}$ ) with myeloma cell proliferation in 244 Bz-treated patients available at GSE9782 [18], using the global gene expression-based proliferation index (GPI) of myeloma devised by Bergsagel et al. [19] as proxy of actual tumor cell proliferation (Fig. 2d). Similarly, we recently reported [13] that FOXM1 message levels in nMM and rMM paralleled the GPI of developed by Hose and his associates [20]. Next, we used eFluxx-ID Gold MDR analysis to demonstrate that upregulation of FOXM1 results in enhanced $\mathrm{ABC}$-transporter efflux-pump activity in myeloma (Fig. 2d). This finding suggested that FOXM1-dependent promotion of cell cycle progression in myeloma may facilitate drug resistance by means of enhanced outflow of myeloma drugs.

\section{Enforced expression of FOXM1 lessens sensitivity to myeloma drugs in vitro}

Because recurrent cancers including rMM may acquire therapy resistance due to alterations in biological pathways in which FOXM1 is involved [21], we wondered whether upregulation of FOXM1 may decrease the sensitivity of myeloma cells to widely used myeloma drugs, such as bortezomib (Bz) and doxorubicin (Dox). We found that enforced expression of FOXM1 renders myeloma partially resistant to both drugs, as evidenced by half-maximal inhibitory concentrations $\left(\mathrm{IC}_{50}\right)$ that, in case of $\mathrm{Bz}$, were 5.6-fold (CAG) and 1.9-fold (XG1) higher in FOXM1 ${ }^{\mathrm{Hi}}$ than FOXM1 ${ }^{\mathrm{N}}$ cells (Fig. 3a, left). In case of Dox, they were 2.9-fold (CAG) and 1.5-fold (XG1) higher (Fig. 3a, right). Flow cytometric measurements of annexin $\mathrm{V}$, a marker of apoptosis, were in agreement with these results as FOXM1 ${ }^{\mathrm{Hi}}$ cells invariably exhibited less drug-induced death than $\mathrm{FOXM1}^{\mathrm{N}}$ cells did. For example, there was a 2.7 -fold difference in CAG cells treated with $\mathrm{Bz}$ (23\% vs. $63 \%$ ) and a 1.5 -fold difference in XG1 cells treated with Dox (49\% vs. $72 \%$, 


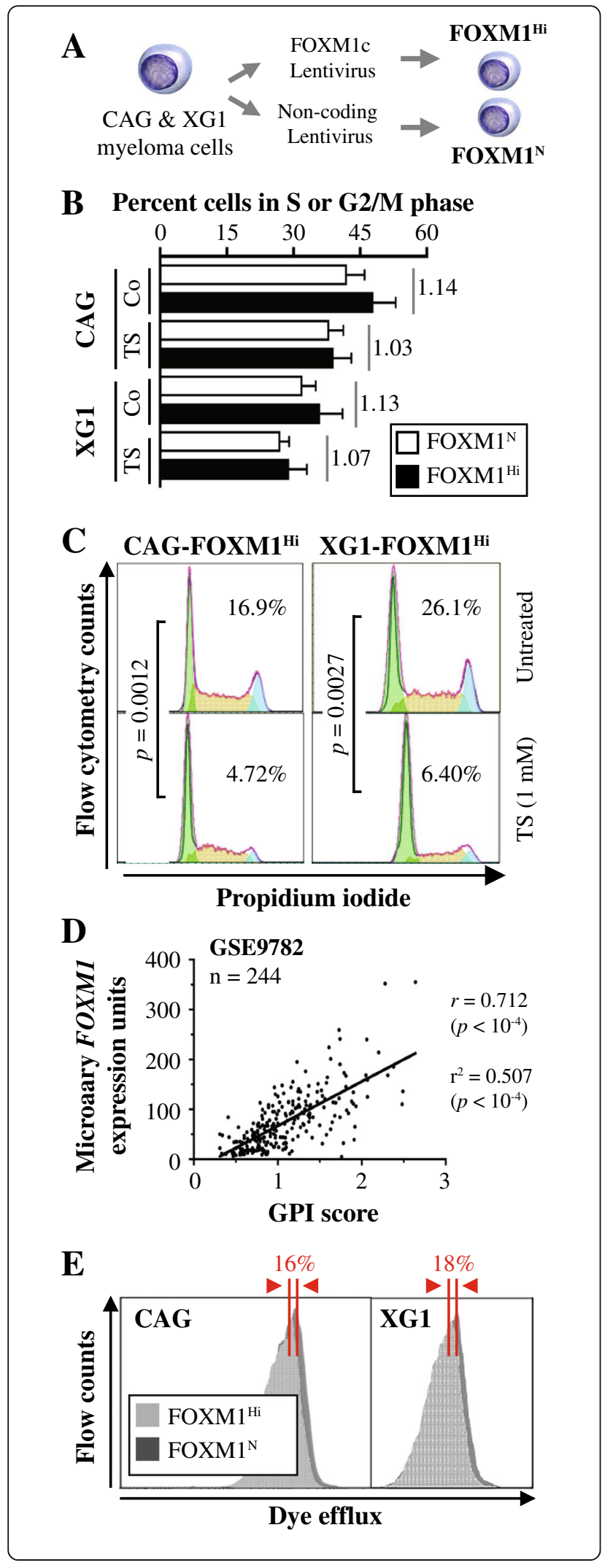

Fig. 2 Constitutive overexpression of FOXM1 promotes growth and survival of myeloma cells in vitro. a Scheme of study design. FOXM1 ${ }^{\mathrm{Hi}}$ and $\mathrm{FOXM}^{\mathrm{N}}$ myeloma cells were generated using lentiviral gene transduction. Two HMCLs, designated CAG and XG1, were used. FOXM1 message levels in FOXM1 ${ }^{\mathrm{Hi}}$ cells, relative to normal levels in FOXM1 ${ }^{\mathrm{N}}$ cells, were significantly elevated in both CAG cells ( $\sim 15$ fold) and XG1 cells ( $\sim 6$-fold). FOXM1 protein levels were only moderately increased: $\sim 50 \%$ and $\sim 30 \%$ in CAG and XG1 cells, respectively. See Figure $4 \mathrm{a}$ in reference [12] for details. b Bar diagrams depicting percent FOXM1 $1^{\mathrm{Hi}}$ and $\mathrm{FOXM1}^{\mathrm{N}} \mathrm{XG1}$ and CAG cells in S or G2/M phase of the active cell cycle. Cells were treated with thiostrepton (TS) or left untreated for use as control (Co). The result is consistent with the analysis of cell proliferation in Figure $4 \mathrm{~b}$ of reference [12], showing that after 1 week in cell culture, the number of viable, actively proliferating FOXM1 $1^{\mathrm{Hi}}$ cells was significantly higher than that of FOXM1 ${ }^{\mathrm{N}}$ cells. c Cell cycle fractions determined by flow cytometry. Treatment of cells using thiostrepton (TS) resulted in a significant drop in cell proliferation, using two-way ANOVA for comparison. d Scatter plot demonstrating positive correlation of FOXM1 expression and myeloma proliferation in 244 Bz-treated patients from the Mayo Clinic. Tumor cell proliferation was scored with the assistance of a gene expression-based proliferation index (GPI) developed by Bergsagel et al. [20]. e Flow cytometric dye efflux histograms of CAG cells (left) and $X G 1$ cells (right), demonstrating heightened $A B C$ transporter drug pump activity in $\mathrm{FOXM1}{ }^{\mathrm{Hi}}$ cells relative to $\mathrm{FOXM1}{ }^{\mathrm{N}}$ cells. Percent differences in mean fluorescence intensity (MFI) were $16 \%$ in case of CAG and $18 \%$ in case of XG1

Fig. 3b). Determination of myeloma growth in soft agar demonstrated the clonogenic advantage of $F O X M 1^{\mathrm{Hi}}$ cells. One example, depicted in Fig. 3c, shows that FOXM1 ${ }^{\mathrm{Hi}}$ CAG cells treated with $2 \mathrm{nM} \mathrm{Bz}$ or left untreated produced $\sim 50 \%$ (right panels) or $\sim 25 \%$ more colonies (left panels), respectively, than $\mathrm{FOXM1}^{\mathrm{N}}$ controls. XG1 cells demonstrated greater differences based on Hi-to-N ratios (Fig. 3d), suggesting that FOXM1 protects the clonogenic growth of these cells under conditions of selective drug pressure even more effectively than that of CAG cells. These findings were of interest in light of published reports that suppression of FOXM1 may sensitize human cancer to killing by genotoxic drugs [22].

\section{Elevation of FOXM1 leads to reduced sensitivity of myeloma xenografts to $\mathrm{Bz}$}

To complement the in vitro findings described above with in vivo data, we determined whether upregulation of FOXM1 results in decreased susceptibility of myeloma to proteasome inhibition (PI). We used human-in-mouse myeloma xenografts treated with $\mathrm{Bz}$ or left untreated (control) as model system. FOXM1 ${ }^{\mathrm{Hi}}$ and FOXM1 ${ }^{\mathrm{N}} \mathrm{CAG}$ cells were transferred under the skin of the left and right flank of NSG mice $(n=10)$, respectively. Treatment of 5 tumor-bearing hosts using daily IP injections of Bz commenced 7 days later. Five tumor-bearing hosts left untreated were used as controls (Fig. 4a). Tumor diameters were measured in 4-day intervals to compare xenograft 


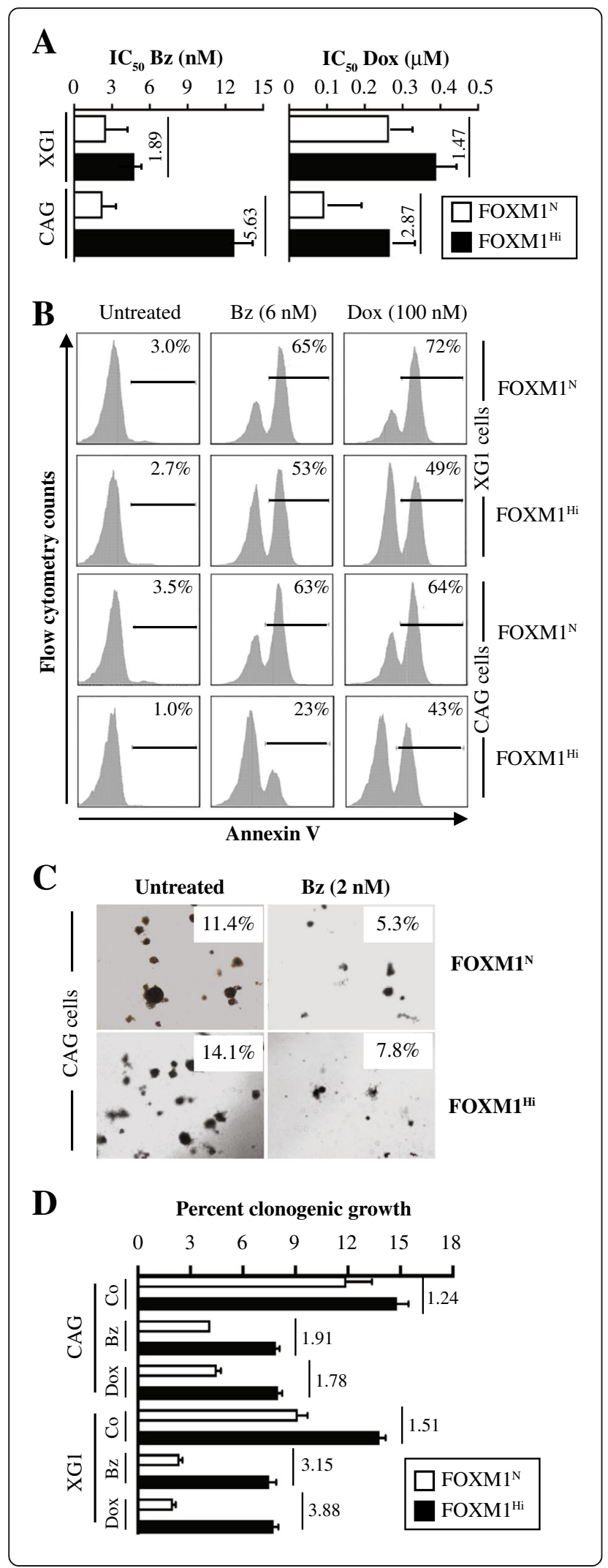

Fig. 3 Upregulation of FOXM1 promotes drug resistance of myeloma in vitro. a Bar diagram depicting the half maximal inhibitory concentrations $\left(\mathrm{IC}_{50}\right)$ of bortezomib (Bz) and doxorubicine (Dox) in $\mathrm{XG1}$ and $\mathrm{CAG}$ myeloma cells expressing elevated (FOXM1 ${ }^{\mathrm{Hi}}$ ) or normal $\left(F O X M 1^{N}\right.$ ) levels of the transcription factor. Cells were grown for 1 week in bulk suspension culture in presence of a $\log _{2}$ dose range of either drug. $I_{50}$ was determined using non-linear regression analysis of dose response curves (GraphPad Prism 7 software). Hi-to-N ratios of $\mathrm{IC}_{50}$ (indicated by vertical short lines and numbers) reflect the magnitude by which overexpression of FOXM1 reduced drug-induced cell killing. $\mathbf{b}$ Representative flow histograms comparing levels of drug-induced apoptosis in paired FOXM1 ${ }^{\mathrm{Hi}}$ / FOXM1 ${ }^{\mathrm{N}}$ samples of XG1 (upper half) and CAG (lower half) cells treated with $6 \mathrm{nM} \mathrm{Bz}$ (center column) or $0.1 \mu \mathrm{M}$ Dox (right column). Cells left untreated were used as control (left column). APC (allophycocyanin)conjugated antibody to annexin $V$ was used to determine the fraction of cells undergoing apoptosis (indicated as percentages above black horizontal lines). In all cases, death was attenuated by enforced expression of FOXM1. c Photographic images of soft-agar plates containing colonies of FOXM1 ${ }^{\mathrm{Hi}}$ and FOXM1 ${ }^{\mathrm{N}}$ CAG myeloma cells. Cells were treated with the indicated dose of bortezomib or left untreated. Clonogenic growth expressed as percentage of cells able to form colonies is given in the insets. $\mathbf{d}$ Bar diagram depicting soft-agar clonogenicity of FOXM1 ${ }^{\mathrm{Hi}} / \mathrm{FOXM1} 1^{\mathrm{N}}$ CAG or XG1 cells treated with 2 nM Bz or $0.1 \mu M$ Dox. Cells left untreated were used as control (Co). The Hi-to- $\mathrm{N}$ ratios of the average colony numbers, determined in triplicate experiments, are indicated by vertical numbers next to vertical lines. The ratios reflect the extent by which overexpression of FOXM1 mitigated drug-dependent inhibition of clonogenic growth

growth rates. FOXM1 ${ }^{\mathrm{Hi}}$ tumors harvested on day 30 (study endpoint) were larger than their FOXM1 ${ }^{\mathrm{N}}$ counterparts in both the Bz treatment arm $(15.2 \pm 1.97 \mathrm{~mm}$ vs $10.4 \pm 0.771 \mathrm{~mm})$ and the control arm $(19.0 \pm 1.31 \mathrm{~mm}$ vs $14.0 \pm 1.73 \mathrm{~mm}$ ) arm (Fig. 4b). This was consistent with FOXM1's growth-promoting activity described above. However, in terms of sensitivity to PI, FOXM1 ${ }^{\mathrm{Hi}}$ tumors were slightly less responsive (by $10 \%$ ) than their FOXM1 ${ }^{\mathrm{N}}$ counterparts on the contralateral side of the same host. Specifically, Bz-dependent growth inhibition of FOXM1 ${ }^{\mathrm{Hi}}$ tumors at study endpoint $(1.32 \pm 0.434 \mathrm{~g}$ in treated mice vs. $2.40 \pm 0.647 \mathrm{~g}$ in mice left untreated) amounted to $45 \%$, whereas that of FOXM1 ${ }^{\mathrm{N}}$ tumors $(0.692 \pm 0.217 \mathrm{~g}$ treated vs $1.54 \pm 0.543 \mathrm{~g}$ untreated $)$ amounted to $55 \%$ (Fig. 4c). This result, however modest it might be, was consistent with published findings that lowering FOXM1 in human cancer cells leads to enhanced PI-induced killing [23].

\section{Binding of FOXM1 to Rb may promote senescence of myeloma cells}

Our recent work has implicated the cyclin-dependent kinase $6(\mathrm{CDK} 6)$ / retinoblastoma $(\mathrm{Rb})$ axis in the mechanism by which FOXM1 promotes myeloma [14]. To confirm the co-regulation of FOXM1 protein levels and the tumor suppressor, $\mathrm{Rb}$, in myeloma, we performed triplicate Western analyses of paired $\mathrm{FOXM1}{ }^{\mathrm{Hi}}$ and FOXM1 $^{\mathrm{N}}$ tumors (Fig. 5a, left). For sake of comparison 


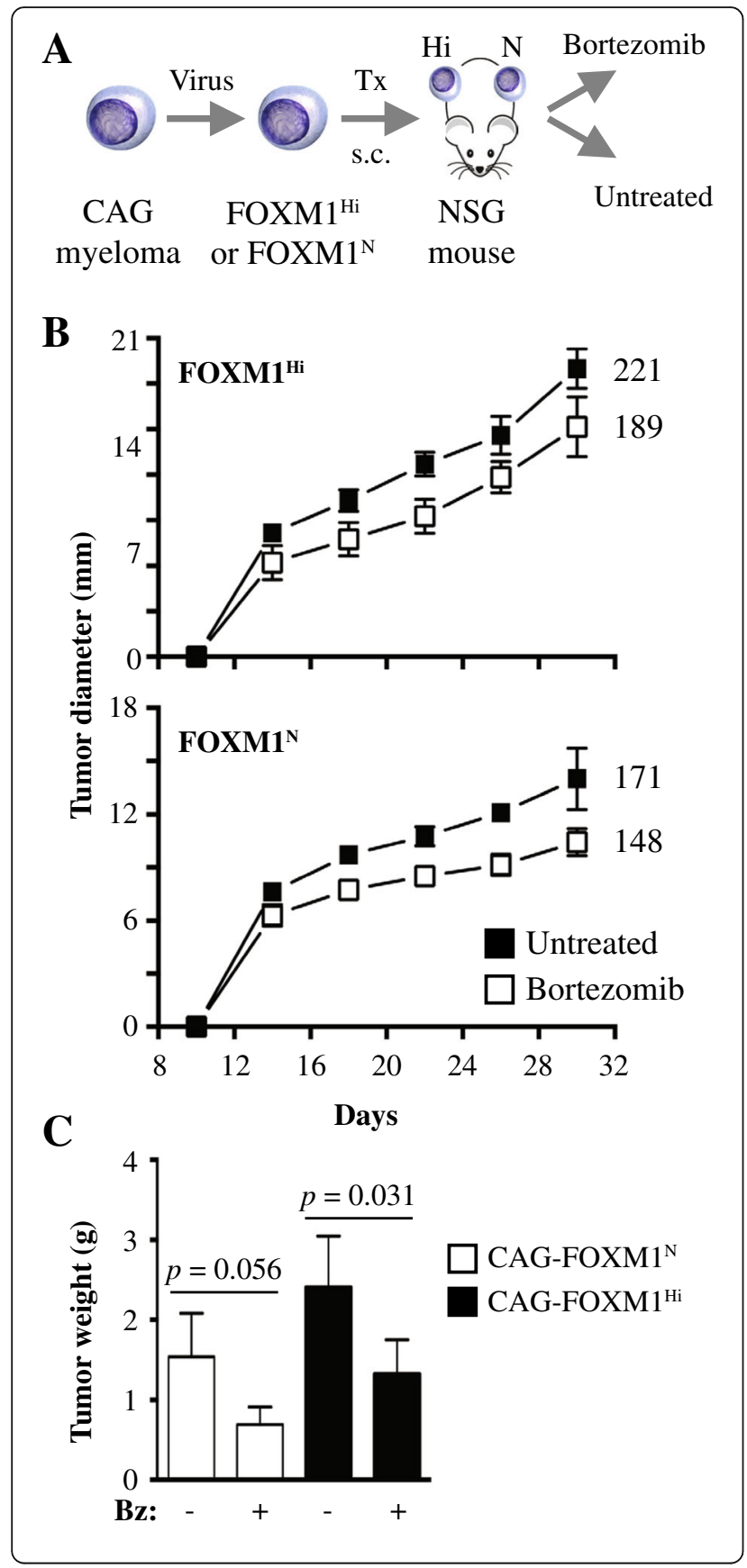

Fig. 4 Upregulation of FOXM1 reduces susceptibility of myeloma xenografts to bortezomib in vivo. a Scheme of study design. FOXM1 ${ }^{\mathrm{Hi}}$ and $\mathrm{FOXM1}^{\mathrm{N}}$ myeloma cells were generated using lentiviral gene transduction as previously described [12]. Cells were subcutaneously (s.c.) xenografted (Tx) into the right and left flank of NSG mice, respectively. Beginning on day 7 following cell transfer, 5 mice were treated with daily administrations of the proteasome inhibitor, bortezomib (Bz, $1 \mu \mathrm{g}$ per gram body weight IV), until study termination on day 30. Five mice were left untreated. In all cases, tumor diameters were measured in 4-day intervals using a caliper, starting on day 10 after xenografting. Xenografts were harvested and weighed on a fine balance at study end. $\mathbf{b}$ Time course of tumor growth in host mice. Mean tumor diameters (squares) and standard deviations of the mean (short vertical lines with error bars) are plotted. In Bz-treated mice, the area under the curve (AUC) of FOXM1 ${ }^{\mathrm{N}}$ tumors (148) was $13 \%$ smaller than that of FOXM1 ${ }^{\mathrm{Hi}}$ (171) tumors. In untreated mice, the AUC of FOXM1 $^{\mathrm{N}}$ tumors (189) was $14 \%$ smaller than that of the FOXM1 ${ }^{\mathrm{N}}$ (221) tumors. c Mean tumor weight at end of study. $\mathrm{FOXM1}^{\mathrm{Hi}}$ xenografts treated with $\mathrm{Bz}(1.32 \pm 0.434 \mathrm{~g})$ were significantly smaller than their untreated counterparts ( $2.40 \pm 0.647 \mathrm{~g})$ using Mann-Whitney's $t$ test $(p=0.031) . F O X M 1^{N}$ xenografts showed the same trend $(1.54 \pm 0.543 \mathrm{~g}$ vs. $0.692 \pm 0.217 \mathrm{~g}$ ) but missed the $5 \%$ threshold of statistical significance $(p=0.056)$. Median tumor weights in all 4 groups were significantly different by Kruskall-Wallis analysis $(p=0.006)$

to $\mathrm{FOXM1}{ }^{\mathrm{Hi}}$, we included FOXM1 ${ }^{\mathrm{Lo}}$ samples from $\mathrm{H} 929$ and ARP1 HMCL cells, in which FOXM1 had been knocked down using lentivirus-delivered RNA interference (Fig. 5a, right). Densitometric analysis of Western blots showed that total $\mathrm{Rb}$ and phosphorylated $\mathrm{Rb}(\mathrm{pRb})$ were increased in FOXM1 ${ }^{\mathrm{Hi}}$ cells by $20-40 \%$, with somewhat higher levels seen in XG1 than CAG cells (Fig. 5b, left). Conversely, $\mathrm{Rb}$ and $\mathrm{pRb}$ were decreased in FOXM1 ${ }^{\text {Lo }}$ cells ( 30 to $50 \%$ ), with the loss of the latter somewhat exceeding that of the former (Fig. 5b, right). Inspired by a large body of evidence that connects the $\mathrm{Rb}$-governed cell fate decision of senescence with important pathways of cancer relapse such as drug resistance, tumor dormancy and tumor stemness [14], we determined whether myeloma cells might express the classic senescence-associated phenotype of $\beta$-galactosidase in a FOXM1-dependent manner. Fig. 5c, left shows that FOXM1 knockdown sufficed to induce $\beta$-gal activity in myeloma. Furthermore, treatment of cells using Dox caused higher $\beta$-gal ${ }^{+}$scores in FOXM1 ${ }^{\mathrm{N}}$ than FOXM1 ${ }^{\mathrm{Hi}}$ cells (Fig. 5c, right). These findings were consistent with published reports on the role of FOXM1 in suppressing cellular senescence in a variety of solid and liquid neoplasms [24].

\section{Discussion}

The main finding of this study is experimental evidence for a role of FOXM1 in advanced myeloma. The new results implicating FOXM1 in drug-resistant disease relapse and the $\beta$-gal ${ }^{+}$phenotype of cellular senescence agree with the well-known pleiotropic function of the transcription factor in cancer cell biology [25]. In both 


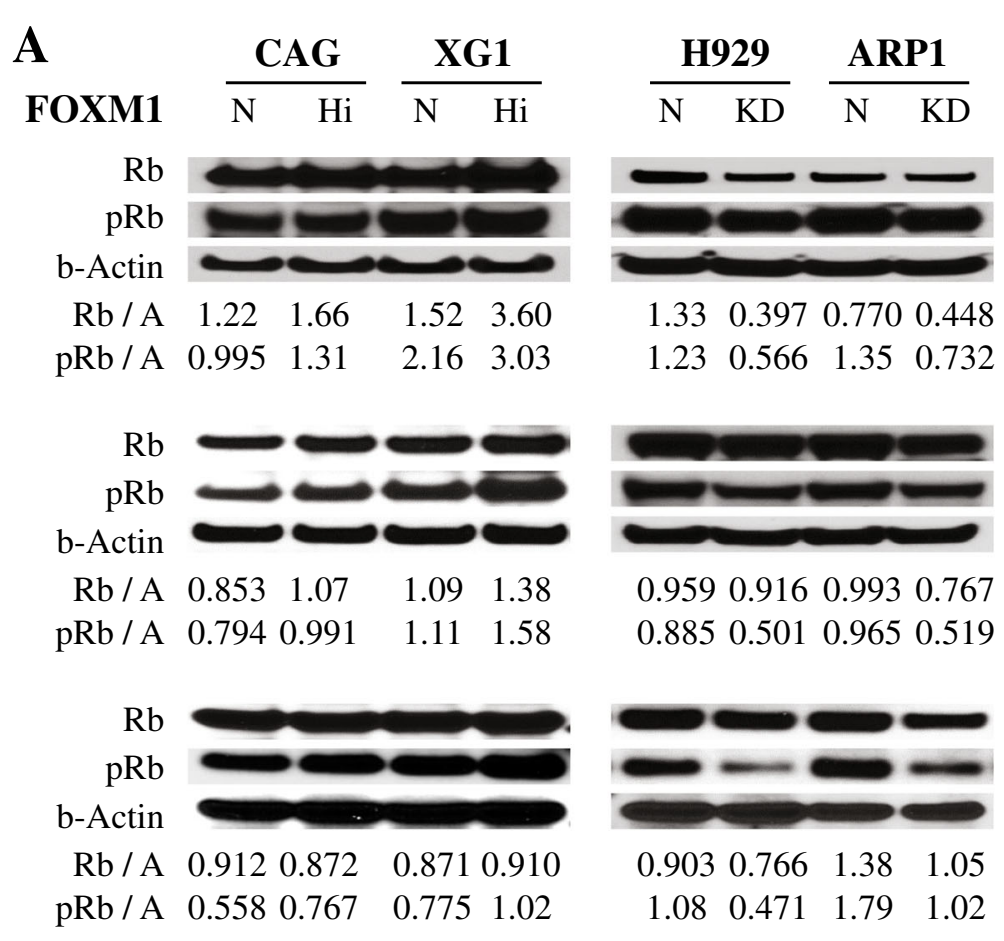

B

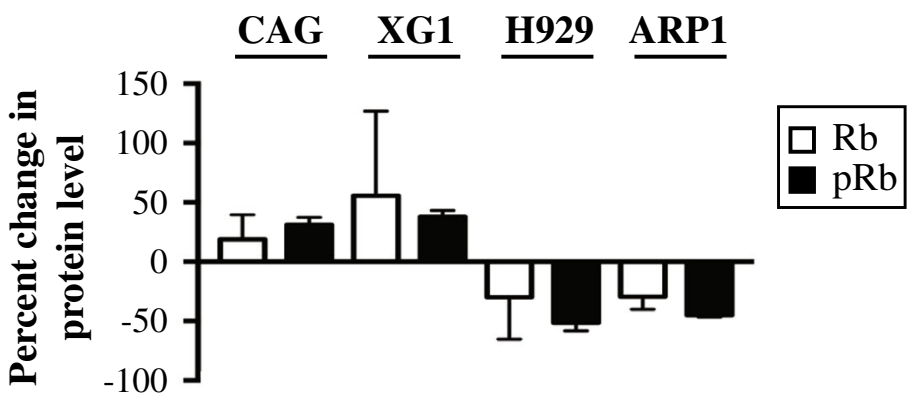

C
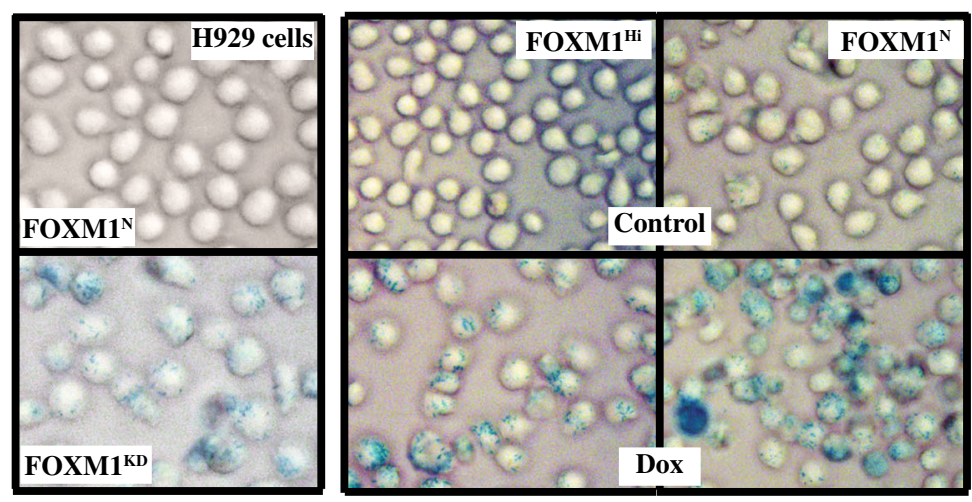

Fig. 5 (See legend on next page.) 
(See figure on previous page.)

Fig. 5 FOXM1/Rb-dependent expression of $\beta$-galactosidase in myeloma cells. a Co-immunoprecipitation (Co-IP) result indicating physical interaction of Rb and FOXM1 in CAG and XG1 myeloma cells. Immunoblots using a specific lgG antibody (Ab) to FOXM1 (following IP with $\mathrm{Ab}$ to Rb) or Rb (following IP with Ab to FOXM1) are shown on top of each other. The lgG isotype control is labeled "IgG." Whole cell lysates not subjected to Co-IP ("Input") were included as an additional control. b Shown on top is a Western blot of total Rb and its activated, phosphorylated form (pRb) in FOXM1 ${ }^{\mathrm{Hi}}$ and FOXM1 ${ }^{\mathrm{N}}$ CAG and XG1 myeloma cells. A similar blot containing samples of FOXM1 ${ }^{\mathrm{KD}}$ and $\mathrm{FOXM1}{ }^{\mathrm{N}} \mathrm{H} 929$ and ARP1 myeloma cells is presented at bottom. The abundance of $\mathrm{Rb}$ and $\mathrm{pRb}$, relative to $\beta$-actin, was determined using densitometry. The ratios are indicated below the blots. $\mathbf{c}$ The upper panel illustrates the elevation of $\beta$-galactosidase ( $\beta$-gal) activity, a classic phenotype of cellular senescence, in FOXM1 ${ }^{\mathrm{KD}}$ H929 cells (bottom) relative to FOXM1 ${ }^{\mathrm{N}}$ controls (top). Cells were not treated with drug. This result was confirmed using paired FOXM1 ${ }^{\mathrm{KD}} / \mathrm{FOXM1}{ }^{\mathrm{N}}$ ARP1 samples (not shown). Depicted in the lower panel is the increased proportion of $\beta$-gal ${ }^{+} X \mathrm{XG}$ cells following treatment with Dox. FOXM1 ${ }^{\mathrm{Hi}}$ cells exhibited a lesser increase than FOXM1 ${ }^{\mathrm{N}}$ cells (not shown). Cells were evaluated using an Olympus BX-51 Light Microscope equipped with an UPLSAPO objective (Olympus) of 40x magnification and 0.95 numerical aperture. The imaging medium was air. The light temperature of the microscope bulb varied between 3000 and $3400 \mathrm{~K}$. Images were acquired with the help of a DP2 digital camera (Olympus) and DP2-BSW imaging software (Olympus), saved as TIF data files, and enhanced — with respect to brightness, contrast, and color balance — using the Adobe Photoshop CS2 Version 9.0.2 software (Adobe Systems, Inc)

solid and liquid cancers, FOXM1 governs a wide spectrum of biological processes, including cell cycle progression, DNA damage repair, self-renewal of stem cells [26] and senescence [24] - all involved in tumor progression and the response of malignancies to cytostatic and targeted treatments [27]. In regard to diverse biological functions attributable to FOXM1 in myeloma, the transcription factor seems to resemble well-established "master" transcription factors of myeloma, such as interferon regulatory factor 4 or IRF4 (a.k.a. MUM1) [28] and the myelocytomatosis oncoprotein MYC [29]. To further put FOXM1's role in myeloma in perspective, it is helpful to recognize that this particular member of the large forkhead box family of proteins is critically involved in the development and outcome of other B-lineage neoplasms; e.g., acute lymphoblastic leukemia [30], diffuse large cell lymphoma [31], chronic lymphocytic leukemia [32] and follicular lymphoma [33]. What is more, an overarching impact of FOXM1 on cancer as a whole has been suggested by a recent pan-cancer meta-analysis of approximately 18 thousand gene expression signatures [34], which identified the FOXM1 regulatory network as a major predictor of adverse outcomes across 39 solid and hematologic malignancies including MM.

Although the molecular mechanism by which FOXM1 promotes drug resistance in myeloma has not yet been elucidated, FOXM1-dependent increases in cell proliferation, NEK2 (NIMA related kinase 2)-dependent CIN

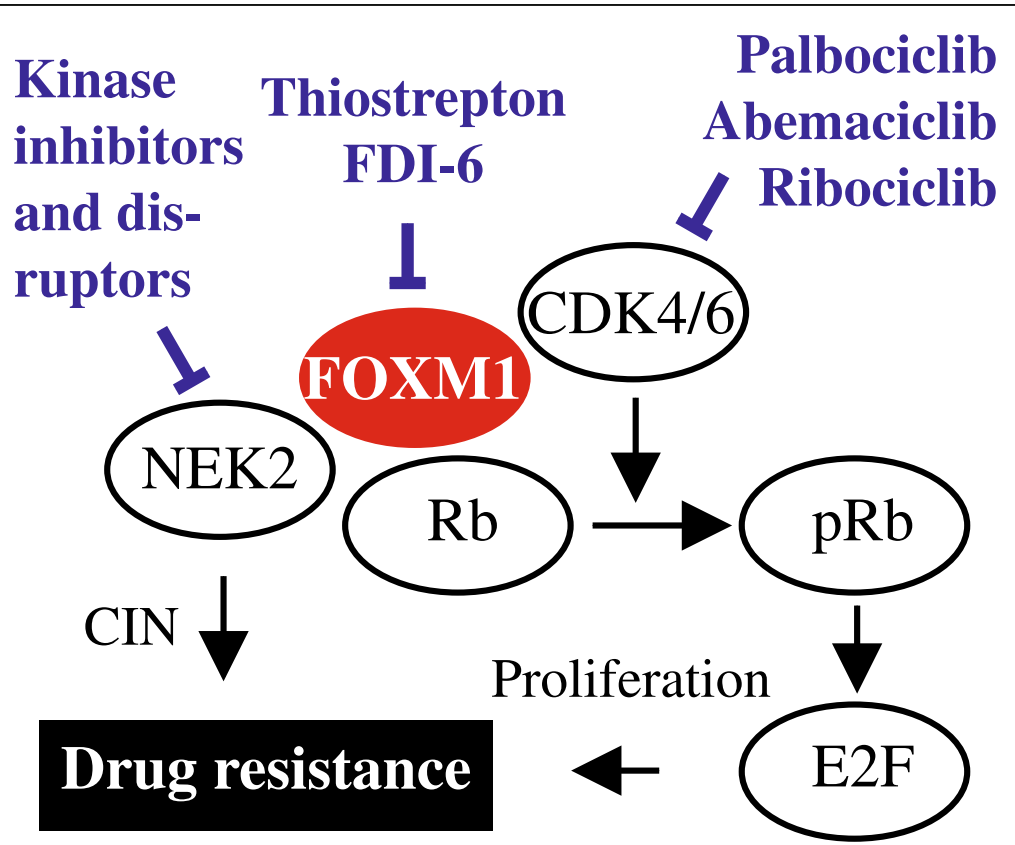

Fig. 6 Therapeutic targeting of the FOXM1 genetic network in myeloma. FOXM1 is a proliferation-associated transcription factor that interacts in myeloma cells with the cyclin D-CDK4/6-Rb-E2F pathway, a key regulator of the G1-to-S cell cycle transition. The findings of this study demonstrate that, in addition to cell cycle progression, FOXM1 promotes drug resistance and, possibly, cellular senescence. Another interaction by which FOXM1 may desensitize myeloma to drug inhibition is NEK2. Small-molecule inhibitors of FOXM1, CDK4/6 and NEK2 are indicated. See main text for details 
(chromosomal instability) and ABC-transporter drugpump activity may be involved [12]. The latter has been repeatedly implicated in drug-resistant solid cancers; e.g., in retinoblastoma [35], bladder cancer [36] and colorectal cancer [37], in which the heightened drug-efflux activity could be functionally linked to FOXM1-dependent upregulation of $\mathrm{ABCC}, \mathrm{ABCG} 2$ and $\mathrm{ABCC} 10$, respectively. Also playing a role may be other pathways of drug resistance that operate in solid tumors [38]; e.g., inhibition of ubiquitination-dependent FOXM1 degradation via interacting proteins, such as OTUB1 (OTU deubiquitinase, ubiquitin aldehyde binding 1) [39]; crosstalk of FOXM1 with other cellular signal transduction pathways, such as HGF / Met (hepatocyte growth factor / Met proto-oncogene, receptor tyrosine kinase) [40] and AKT (AKT serine / threonine kinase 1) [41]; and metabolic changes that effect increased oxidative defense capacity, as seen in radio-resistant head and neck squamous cell carcinoma [42]. Targeting the interactions and pathways described above - perhaps in conjunction with targeting FOXM1 directly using established [43] or emerging [44] small-drug inhibitors - may afford the re-sensitization of relapsed FOXM1 ${ }^{\text {High }}$ myeloma to $\mathrm{Bz}$ and other drugs that were effective at earlier stages of myeloma therapy. A variety of molecularly targeted chemo-sensitization approaches of this sort are pursued in myeloma [45] - all attempting to build on findings in B-ALL that demonstrate that drug resistance in malignant B lymphocytes may be overcome by suppression of FOXM1 [46].

Several limitations of our study exist. First among these is the need to confirm the findings on FOXM1dependent drug resistance in primary tumor cells. Sequential $\mathrm{nMM} \rightarrow \mathrm{rMM}$ samples of fractionated malignant bone marrow plasma cells obtained from patients with new and relapsed myeloma may lend themselves to that end. In this context, we should also acknowledge that our xenograft approach for testing the Bz response in vivo was not a true study of cancer relapse; instead, it merely assessed drug-dependent growth inhibition in vivo. Genetically engineered mouse models of human myeloma - in which spontaneously arising tumors can be put into remission using clinically relevant myeloma drugs, and the mice can be kept alive until relapsed tumors require salvage treatment - may mimic the situation of patients with rMM more accurately. Two validated mouse models, designated Vк-Myc and IL6iMyc, are available for that purpose [47-50]. Another limitation of this study concerns the involvement of cellular senescence in drug-resistant myeloma. Although $\beta$-gal activity is a well-established phenotype of cellular senescence in many types of cancer including MM [51, 52], additional research is warranted to demonstrate the mechanistic link to the FOXM1-Rb pathway. Mechanisms of FOXM1-dependent senescence elucidated in neoplasms other than myeloma [53] include enhancement of Bmi-1 expression, as seen in the NIH3T3 model [54]; overexpression of miR-370, observed in AML [55]; and inhibition of the CDK4/6-FOXM1 axis by genetic means, such as enforced expression of miR-506 in ovarian cancer [56], or pharmacologic means, such as small-drug CDK inhibition in neuroblastoma [57].

\section{Conclusion}

We now know that FOXM1 is a high-risk myeloma gene in newly diagnosed patients [12] that undergoes further upregulation in the majority of cases upon tumor relapse [13]. FOXM1's interaction in myeloma cells with NEK2 (NIMA-related kinase 2) and the CDK4/6-Rb-E2F axis $[12,13]$ is of interest from a therapeutic viewpoint because CDK inhibition may be effective in myeloma [12, 58-60]. Moreover, NEK2 - a well-established transcriptional target of FOXM1 in cancer $[61,62]$ that has been shown to drive drug resistance in myeloma and other malignancies [63-65] - can be targeted with the help of small compounds that inhibit kinase activity [66] or trigger target degradation indirectly by means of a mechanism that involves the disruption of NEK2 binding to the kinetochore complex component NDC80 / HEC1 [67]. Figure 6 depicts the emerging FOXM1 genetic network in myeloma. Small-drug inhibitors targeting this network may overcome drug resistance in tumors in which the transcription factor is highly expressed.

\section{Additional file}

\begin{abstract}
Additional file 1: Figure S1. Quantitative, reverse transcription (RT) polymerase chain reaction ( $q R T-P C R$ ) analysis of FOXM1 gene expression in 8 myeloma patients for which 3 sequential CD138+ fractionated bone marrow tumor samples at baseline (white columns, newly diagnosed disease), initiation of HDT (high-dose therapy) and autologous hematopoietic stem cell transplantation (ASCT) therapy (grey columns) and consolidation / maintenance therapy (black columns) were available. In the course of the latter, three patiens (1, 2 and 8) and one patient (7) experienced a clinically significant and incipient FOXM1 $1^{\text {High }}$ relapse, respectively. Total RNA was extracted using Quick-RNA MiniPrep (Zymo Research) and reverse transcribed using oligo dT primers and SuperScript III RT (Invitrogen). Data analysis relied on the $\Delta \Delta$ Ct method. Primers were purchased from Integrated DNA Technologies (Coralville, lowa). Sequences are available upon request. All increases in FOXM1 gene expression are relative to the patient-specific baseline value, which was set at 1. All patients were consented in accordance with rules and regulations of the US Food and Drug Administration and the Declaration of Helsinki. Tumor samples were collected with institutional approval supplied with IRB 201503809 entitled "FOXM1 role in myeloma." (PDF 1499 kb)
\end{abstract}

\section{Acknowledgements}

Expert technical assistance provided by staff of The University of lowa Laboratory Animal Care and Resources Facility, Central Microscopy Research Facility, and Flow Cytometry and Genomics Cores is gratefully acknowledged.

\section{Funding}

This work was supported by grants from the National Natural Science Foundation of China (NSFC), (81500166, 81600177, 81770220 and 81670200 to $Y Y$ and $C G$ and by grants from the Natural Science Foundation of Jiangsu 
Province, BK20160048 to YY and BK20161041 to CG. This work was also supported by NIH R01CA152105 and grants from the Multiple Myeloma Research Foundation, International Myeloma Foundation and American Society of Hematology (ASH) Bridge Funding Program (all to FZ). Additional assistance was provided by NCl Core Grant P30CA086862 in support of The University of lowa Holden Comprehensive Cancer Center. Support from ASH's Bridge Grant Program and NIH grants R21CA187388 and R01CA151354 (all to SJ) is also gratefully acknowledged.

\section{Availability of data and materials}

Please contact the co-senior authors with requests for data, reagents, constructs, and materials.

\section{Authors' contributions}

CG and XJ carried out bench work and performed in vitro and in vivo studies using myeloma cells. CH and R S carried out histopathologic and statistical analyses. FZ and GT evaluated gene expression and clinical outcome data and provided expertise on myeloma treatment. YY and S J conceived, designed and coordinated the study and drafted the manuscript. All authors read, commented on, and approved the final manuscript.

\section{Ethics approval and consent to participate}

The University of lowa Institutional Review Board approved the study, including the use of de-identified patient tissue samples. All patients provided written informed consent and their anonymity was maintained throughout the study.

\section{Consent for publication}

Not applicable.

\section{Competing interests}

The authors declare that they have no competing interests.

\section{Publisher's Note}

Springer Nature remains neutral with regard to jurisdictional claims in published maps and institutional affiliations.

\section{Author details}

${ }^{1}$ The Third Affiliated Hospital, Nanjing University of Chinese Medicine, Nanjing 210023, China. ${ }^{2}$ Key Laboratory of Acupuncture and Medicine Research, Ministry of Education, Nanjing University of Chinese Medicine, Nanjing 210023, China. ${ }^{3}$ Department of Pathology, The University of lowa Roy J. and Lucille A. Carver College of Medicine, lowa City, lowa 52242, USA. ${ }^{4}$ Iowa Institute for Genetics, The University of lowa Roy J. and Lucille A. Carver College of Medicine, lowa City, lowa 52242, USA. ${ }^{5}$ Department of Internal Medicine, The University of lowa Roy J. and Lucille A. Carver College of Medicine, lowa City, lowa 52242, USA. ${ }^{6}$ Holden Comprehensive Cancer Center, The University of lowa Roy J. and Lucille A. Carver College of Medicine, lowa City, lowa 52242, USA. ${ }^{7}$ Department of Medicine, Medical College of Wisconsin, Milwaukee, WI 53213, USA.

\section{Received: 6 April 2018 Accepted: 30 October 2018} Published online: 21 November 2018

\section{References}

1. Siegel RL, Miller KD, Jemal A. Cancer statistics, 2016. CA Cancer J Clin. 2016; 66(1):7-30.

2. Rajkumar SV, Dimopoulos MA, Palumbo A, Blade J, Merlini G, Mateos MV, Kumar S, Hillengass J, Kastritis E, Richardson P, et al. International myeloma working group updated criteria for the diagnosis of multiple myeloma. Lancet Oncol. 2014;15(12):e538-48.

3. Rollig C, Knop S, Bornhauser M. Multiple myeloma. Lancet. 2015;385(9983): 2197-208.

4. Barlogie B, Mitchell A, van Rhee F, Epstein J, Morgan GJ, Crowley J. Curing myeloma at last: defining criteria and providing the evidence. Blood. 2014; 124(20):3043-51.

5. Tang M, Zhao R, van de Velde H, Tross JG, Mitsiades C, Viselli S, Neuwirth R, Esseltine DL, Anderson K, Ghobrial IM, et al. Myeloma cell dynamics in response to treatment supports a model of hierarchical differentiation and clonal evolution. Clin Cancer Res. 2016;22(16):4206-14.
6. Kortum KM, Mai EK, Hanafiah NH, Shi CX, Zhu YX, Bruins L, Barrio S, Jedlowski $\mathrm{P}$, Merz $\mathrm{M}, \mathrm{Xu}$ J, et al. Targeted sequencing of refractory myeloma reveals a high incidence of mutations in CRBN and Ras pathway genes. Blood. 2016;128(9):1226-33.

7. Weinhold N, Ashby C, Rasche L, Chavan SS, Stein C, Stephens OW, Tytarenko R, Bauer MA, Meissner T, Deshpande S, et al. Clonal selection and double hit events involving tumor suppressor genes underlie relapse from chemotherapy: myeloma as a model. Blood. 2016;128(13):1735-44.

8. Agirre X, Castellano G, Pascual M, Heath S, Kulis M, Segura V, Bergmann A, Esteve A, Merkel A, Raineri E, et al. Whole-epigenome analysis in multiple myeloma reveals DNA hypermethylation of B cell-specific enhancers. Genome Res. 2015;25(4):478-87.

9. Gooding S, Edwards CM. New approaches to targeting the bone marrow microenvironment in multiple myeloma. Curr Opin Pharmacol. 2016;28:43-9.

10. Nikesitch $\mathrm{N}$, Ling SC. Molecular mechanisms in multiple myeloma drug resistance. J Clin Pathol. 2016;69(2):97-101.

11. Miannay B, Minvielle $S$, Roux O, Drouin P, Avet-Loiseau H, GuerinCharbonnel C, Gouraud W, Attal M, Facon T, Munshi NC, et al. Logic programming reveals alteration of key transcription factors in multiple myeloma. Sci Rep. 2017;7(1):9257.

12. Gu C, Yang Y, Sompallae R, Xu H, Tompkins VS, Holman C, Hose D, Goldschmidt H, Tricot G, Zhan F, et al. FOXM1 is a therapeutic target for high-risk multiple myeloma. Leukemia. 2016;30(4):873-82.

13. Gu C, Holman C, Sompallae R, Jing X, Tomasson M, Hose D, Seckinger A, Zhan F, Tricot G, Goldschmidt H, et al. Upregulation of FOXM1 in a subset of relapsed myeloma results in poor outcome. Blood Cancer J. 2018;8(2):22.

14. He Z, O'Neal J, Wilson WC, Mahajan N, Luo J, Wang Y, Su MY, Lu L, Skeath JB, Bhattacharya D, et al. Deletion of Rb1 induces both hyperproliferation and cell death in murine germinal center B cells. Exp Hematol. 2016;44(3):161-5.

15. Zhan F, Huang Y, Colla S, Stewart JP, Hanamura I, Gupta S, Epstein J, Yaccoby S, Sawyer J, Burington B, et al. The molecular classification of multiple myeloma. Blood. 2006;108(6):2020-8.

16. Seckinger A, Meissner T, Moreaux J, Depeweg D, Hillengass J, Hose K, Reme T, Rosen-Wolff A, Jauch A, Schnettler R, et al. Clinical and prognostic role of annexin A2 in multiple myeloma. Blood. 2012;120(5):1087-94.

17. Hegde NS, Sanders DA, Rodriguez R, Balasubramanian S. The transcription factor FOXM1 is a cellular target of the natural product thiostrepton. Nat Chem. 2011;3(9):725-31.

18. Mulligan G, Mitsiades C, Bryant B, Zhan F, Chng WJ, Roels S, Koenig E, Fergus A, Huang $Y$, Richardson $P$, et al. Gene expression profiling and correlation with outcome in clinical trials of the proteasome inhibitor bortezomib. Blood. 2007;109(8):3177-88.

19. Bergsagel PL, KuehI WM, Zhan F, Sawyer J, Barlogie B, Shaughnessy J Jr. Cyclin D dysregulation: an early and unifying pathogenic event in multiple myeloma. Blood. 2005;106(1):296-303.

20. Hose D, Reme T, Hielscher T, Moreaux J, Messner T, Seckinger A, Benner A, Shaughnessy JD Jr, Barlogie B, Zhou Y, et al. Proliferation is a central independent prognostic factor and target for personalized and risk-adapted treatment in multiple myeloma. Haematologica. 2011;96(1):87-95.

21. Khongkow P, Gomes AR, Gong C, Man EP, Tsang JW, Zhao F, Monteiro LJ, Coombes RC, Medema RH, Khoo US, et al. Paclitaxel targets FOXM1 to regulate KIF20A in mitotic catastrophe and breast cancer paclitaxel resistance. Oncogene. 2016;35(8):990-1002.

22. Halasi M, Gartel AL. Suppression of FOXM1 sensitizes human cancer cells to cell death induced by DNA-damage. PLoS One. 2012;7(2):e31761.

23. Pandit B, Gartel AL. FoxM1 knockdown sensitizes human cancer cells to proteasome inhibitor-induced apoptosis but not to autophagy. Cell cycle (Georgetown, Tex). 2011;10(19):3269-73.

24. Yao S, Fan LY, Lam EW. The FOXO3-FOXM1 axis: a key cancer drug target and a modulator of cancer drug resistance. Semin Cancer Biol. 2018;50:77-89.

25. Bella L, Zona S, Nestal de Moraes G, Lam EW. FOXM1: a key oncofoetal transcription factor in health and disease. Semin Cancer Biol. 2014;29:32-9.

26. Zona S, Bella L, Burton MJ, Nestal de Moraes G, Lam EW. FOXM1: an emerging master regulator of DNA damage response and genotoxic agent resistance. Biochim Biophys Acta. 2014;1839(11):1316-22.

27. Koo CY, Muir KW, Lam EW. FOXM1: from cancer initiation to progression and treatment. Biochim Biophys Acta. 2012;1819(1):28-37.

28. Shaffer AL, Emre NC, Lamy L, Ngo VN, Wright G, Xiao W, Powell J, Dave S, Yu X, Zhao H, et al. IRF4 addiction in multiple myeloma. Nature. 2008; 454(7201):226-31. 
29. Keats JJ, Chesi M, Egan JB, Garbitt VM, Palmer SE, Braggio E, Van Wier S, Blackburn PR, Baker AS, Dispenzieri A, et al. Clonal competition with alternating dominance in multiple myeloma. Blood. 2012;120(5):1067-76.

30. Buchner M, Park E, Geng H, Klemm L, Flach J, Passegue E, Schjerven H, Melnick A, Paietta E, Kopanja D, et al. Identification of FOXM1 as a therapeutic target in B-cell lineage acute lymphoblastic leukaemia. Nat Commun. 2015;6:6471.

31. Uddin S, Hussain AR, Ahmed M, Siddiqui K, Al-Dayel F, Bavi P, Al-Kuraya KS Overexpression of FoxM1 offers a promising therapeutic target in diffuse large B-cell lymphoma. Haematologica. 2012;97(7):1092-100.

32. Motiwala T, Kutay H, Zanesi N, Frissora FW, Mo X, Muthusamy N, Jacob ST. PTPROt-mediated regulation of p53/Foxm1 suppresses leukemic phenotype in a CLL mouse model. Leukemia. 2015;29(6):1350-9.

33. Bisikirska B, Bansal M, Shen Y, Teruya-Feldstein J, Chaganti R, Califano A. Elucidation and pharmacological targeting of novel molecular drivers of follicular lymphoma progression. Cancer Res. 2016;76(3):664-74.

34. Gentles AJ, Newman AM, Liu CL, Bratman SV, Feng W, Kim D, Nair VS, Xu Y, Khuong A, Hoang CD, et al. The prognostic landscape of genes and infiltrating immune cells across human cancers. Nat Med. 2015;21(8):938-45.

35. Zhu X, Xue L, Yao Y, Wang K, Tan C, Zhuang M, Zhou F, Zhu L. The FoxM1ABCC4 axis mediates carboplatin resistance in human retinoblastoma Y-79 cells. Acta Biochim Biophys Sin Shanghai. 2018;50(9):914-20.

36. Roh YG, Mun MH, Jeong MS, Kim WT, Lee SR, Chung JW, Kim SI, Kim TN, Nam JK, Leem SH. Drug resistance of bladder cancer cells through activation of ABCG2 by FOXM1. BMB Rep. 2018;51(2):98-103.

37. Xie T, Geng J, Wang Y, Wang L, Huang M, Chen J, Zhang K, Xue L, Liu X, Mao $X$, et al. FOXM1 evokes 5 -fluorouracil resistance in colorectal cancer depending on ABCC10. Oncotarget. 2017;8(5):8574-89.

38. Wang $Y$, Wen L, Zhao SH, Ai ZH, Guo JZ, Liu WC. FoxM1 expression is significantly associated with cisplatin-based chemotherapy resistance and poor prognosis in advanced non-small cell lung cancer patients. Lung Cancer. 2013;79(2):173-9.

39. Karunarathna U, Kongsema M, Zona S, Gong C, Cabrera E, Gomes AR, Man EP, Khongkow P, Tsang JW, Khoo US, et al. OTUB1 inhibits the ubiquitination and degradation of FOXM1 in breast cancer and epirubicin resistance. Oncogene. 2016;35(11):1433-44.

40. Cui J, Xia T, Xie D, Gao Y, Jia Z, Wei D, Wang L, Huang S, Quan M, Xie K. HGF/Met and FOXM1 form a positive feedback loop and render pancreatic cancer cells resistance to Met inhibition and aggressive phenotypes. Oncogene. 2016;35(36):4708-18.

41. Wang $Y$, Zhang $W$, Wen $L$, Yang $H$, Wen M, Yun $Y$, Zhao L, Zhu X, Tian L,

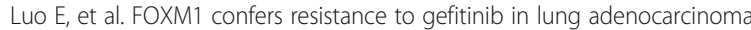
via a MET/AKT-dependent positive feedback loop. Oncotarget. 2016;7(37): 59245-59.

42. Eckers JC, Kalen AL, Sarsour EH, Tompkins VS, Janz S, Son JM, Doskey CM, Buettner GR, Goswami PC. Forkhead box M1 regulates quiescenceassociated radioresistance of human head and neck squamous carcinoma cells. Radiat Res. 2014;182(4):420-9.

43. Halasi M, Gartel AL. Targeting FOXM1 in cancer. Biochem Pharmacol. 2013; 85(5):644-52.

44. Wever WJ, Bogart JW, Baccile JA, Chan AN, Schroeder FC, Bowers AA. Chemoenzymatic synthesis of thiazolyl peptide natural products featuring an enzyme-catalyzed formal [4 + 2] cycloaddition. J Am Chem Soc. 2015; 137(10):3494-7.

45. Shah SP, Lonial S, Boise LH. When Cancer fights Back: multiple myeloma, proteasome inhibition, and the heat-shock response. Mol Cancer Res. 2015; 13(8):1163-73.

46. Consolaro F, Basso G, Ghaem-Magami S, Lam EW, Viola G. FOXM1 is overexpressed in B-acute lymphoblastic leukemia (B-ALL) and its inhibition sensitizes B-ALL cells to chemotherapeutic drugs. Int J Oncol. 2015;47(4): 1230-40.

47. Chesi M, Matthews GM, Garbitt VM, Palmer SE, Shortt J, Lefebure M, Stewart AK, Johnstone RW, Bergsagel PL. Drug response in a genetically engineered mouse model of multiple myeloma is predictive of clinical efficacy. Blood. 2012;120(2):376-85.

48. Chesi M, Robbiani DF, Sebag M, Chng WJ, Affer M, Tiedemann R, Valdez R, Palmer SE, Haas SS, Stewart AK, et al. AID-dependent activation of a MYC transgene induces multiple myeloma in a conditional mouse model of post-germinal center malignancies. Cancer Cell. 2008;13(2):167-80.

49. Duncan $K$, Rosean TR, Tompkins VS, Olivier A, Sompallae R, Zhan F, Tricot G, Acevedo MR, Ponto LL, Walsh SA, et al. (18)F-FDG-PET/CT imaging in an IL-
6- and MYC-driven mouse model of human multiple myeloma affords objective evaluation of plasma cell tumor progression and therapeutic response to the proteasome inhibitor ixazomib. Blood Cancer J. 2013;3:e165.

50. Rutsch S, Neppalli VT, Shin DM, DuBois W, Morse HC 3rd, Goldschmidt H, Janz S. IL-6 and MYC collaborate in plasma cell tumor formation in mice. Blood. 2010;115(9):1746-54.

51. Delmore JE, Issa GC, Lemieux ME, Rahl PB, Shi J, Jacobs HM, Kastritis E, Gilpatrick T, Paranal RM, Qi J, et al. BET bromodomain inhibition as a therapeutic strategy to target C-Myc. Cell. 2011;146(6):904-17.

52. Gorgun G, Calabrese E, Hideshima T, Ecsedy J, Perrone G, Mani M, Ikeda H, Bianchi G, Hu Y, Cirstea D, et al. A novel Aurora-a kinase inhibitor MLN8237 induces cytotoxicity and cell-cycle arrest in multiple myeloma. Blood. 2010; 115(25):5202-13.

53. Zeng J, Wang L, Li Q, Li W, Bjorkholm M, Jia J, Xu D. FoxM1 is up-regulated in gastric cancer and its inhibition leads to cellular senescence, partially dependent on p27 kip1. J Pathol. 2009;218(4):419-27.

54. Li SK, Smith DK, Leung WY, Cheung AM, Lam EW, Dimri GP, Yao KM. FoxM1c counteracts oxidative stress-induced senescence and stimulates Bmi-1 expression. J Biol Chem. 2008;283(24):16545-53.

55. Zhang X, Zeng J, Zhou M, Li B, Zhang Y, Huang T, Wang L, Jia J, Chen C. The tumor suppressive role of miRNA-370 by targeting FoxM1 in acute myeloid leukemia. Mol Cancer. 2012;11.

56. Liu G, Sun Y, Ji P, Li X, Cogdell D, Yang D, Parker Kerrigan BC, Shmulevich I, Chen K, Sood AK, et al. MiR-506 suppresses proliferation and induces senescence by directly targeting the CDK4/6-FOXM1 axis in ovarian cancer. J Pathol. 2014;233(3):308-18.

57. Rader J, Russell MR, Hart LS, Nakazawa MS, Belcastro LT, Martinez D, Li Y, Carpenter EL, Attiyeh EF, Diskin SJ, et al. Dual CDK4/CDK6 inhibition induces cell-cycle arrest and senescence in neuroblastoma. Clin Cancer Res. 2013; 19(22):6173-82

58. Menu E, Garcia J, Huang X, Di Liberto M, Toogood PL, Chen I, Vanderkerken K, Chen-Kiang S. A novel therapeutic combination using PD 0332991 and bortezomib: study in the 5T33MM myeloma model. Cancer Res. 2008;68(14): 5519-23.

59. Niesvizky R, Badros AZ, Costa $\amalg$, Ely SA, Singhal SB, Stadtmauer EA, Haideri NA, Yacoub A, Hess G, Lentzsch S, et al. Phase 1/2 study of cyclindependent kinase (CDK)4/6 inhibitor palbociclib (PD-0332991) with bortezomib and dexamethasone in relapsed/refractory multiple myeloma. Leukemia \& lymphoma. 2015;56:3320-8.

60. Kumar SK, LaPlant B, Chng WJ, Zonder J, Callander N, Fonseca R, Fruth B, Roy V, Erlichman C, Stewart AK, et al. Dinaciclib, a novel CDK inhibitor, demonstrates encouraging single-agent activity in patients with relapsed multiple myeloma. Blood. 2015;125(3):443-8.

61. Nischalke HD, Schmitz V, Luda C, Aldenhoff K, Berger C, Feldmann G, Sauerbruch T, Spengler U, Nattermann J. Detection of IGF2BP3, HOXB7, and NEK2 mRNA expression in brush cytology specimens as a new diagnostic tool in patients with biliary strictures. PLoS One. 2012;7(8):e42141.

62. Calvisi DF, Pinna F, Ladu S, Pellegrino R, Simile MM, Frau M, De Miglio MR, Tomasi ML, Sanna V, Muroni MR, et al. Forkhead box M1B is a determinant of rat susceptibility to hepatocarcinogenesis and sustains ERK activity in human HCC. Gut. 2009;58(5):679-87.

63. Zhou W, Yang Y, Xia J, Wang H, Salama ME, Xiong W, Xu H, Shetty S, Chen $T$, Zeng $Z$, et al. NEK2 induces drug resistance mainly through activation of efflux drug pumps and is associated with poor prognosis in myeloma and other cancers. Cancer Cell. 2013;23(1):48-62

64. Liu X, Gao Y, Lu Y, Zhang J, Li L, Yin F. Upregulation of NEK2 is associated with drug resistance in ovarian cancer. Oncol Rep. 2014;31(2):745-54.

65. Marina M, Saavedra HI. Nek2 and Plk4: prognostic markers, drivers of breast tumorigenesis and drug resistance. Front Biosci (Landmark Ed). 2014;19:352-65.

66. Innocenti P, Woodward H, O'Fee L, Hoelder S. Expanding the scope of fused pyrimidines as kinase inhibitor scaffolds: synthesis and modification of pyrido[3,4d]pyrimidines. Organic \& biomolecular chemistry. 2015;13(3):893-904.

67. Hu CM, Zhu J, Guo XE, Chen W, Qiu XL, Ngo B, Chien R, Wang YV, Tsai CY, Wu G, et al. Novel small molecules disrupting Hec1/Nek2 interaction ablate tumor progression by triggering Nek2 degradation through a death-trap mechanism. Oncogene. 2015;34(10):1220-30. 